\title{
PHOTOSENSITIZATION OF IN VITRO BIOFILMS FORMED ON DENTURE BASE RESIN
}

\section{Karina Matthes de Freitas-Pontes, PhD, ${ }^{a}$ \\ Carlos Eduardo de Albuquerque Gomes, DDS, Bruna Marjorie Dias Frota de Carvalho, DDS, ${ }^{c}$ Rafael de Sousa Carvalho Sabóia, ${ }^{d}$ and Bruna Albuquerque Garcia ${ }^{e}$ School of Pharmacy, Dentistry and Nursing, Federal University of Ceará, Ceará, Brazil}

Statement of problem. Proper sterilization or disinfection of removable prostheses and surgical guides has been problematic in dental practice because of the absence of simple and low-cost techniques that do not cause damage to acrylic resins.

Purpose. The purpose of this study was to study the effect of photodynamic therapy against Streptococcus mutans, Staphylococcus aureus, Escherichia coli, Pseudomonas aeruginosa, and Candida albicans biofilms formed on acrylic resin specimens.

Material and methods. The specimens were sterilized in ethylene oxide gas and submitted to in vitro biofilm growth. The photodynamic therapy consisted of the application of $0.05 \%$ methylene blue $(\mathrm{P}+)$ conjugated to irradiation with a light-emitting-diode of $630 \mathrm{~nm}$ and $150 \mathrm{~mW}(\mathrm{~L}+)$. The specimens were randomly divided into groups $(\mathrm{n}=5)$ : negative control $(\mathrm{P}-\mathrm{L}-)$; stained and irradiated at $10 \mathrm{~J} / \mathrm{cm}^{2}(\mathrm{P}+\mathrm{L}+10)$; stained and irradiated at $30 \mathrm{~J} / \mathrm{cm}^{2}(\mathrm{P}+\mathrm{L}+30)$; stained and not irradiated $(P+L-)$; not stained and irradiated at $10 \mathrm{~J} / \mathrm{cm}^{2}(P-L+10)$; not stained and irradiated at $30 \mathrm{~J} / \mathrm{cm}^{2}(P-L+30)$; and gold standard (GS), sterilized. Afterward, the specimens were submitted to contact with culture medium agar for 10 minutes in petri plates, which were incubated for 48 hours at $37^{\circ} \mathrm{C}$. The number of colony-forming units was obtained, and the data were expressed according to scores $(1=0 ; 2=1-10 ; 3=11-100 ; 4=101-1000)$ and analyzed by the Friedman and Dunn tests $(\alpha=.05)$.

Results. Streptococcus mutans was sensitized by $(\mathrm{P}+\mathrm{L}-)$; $P$ aeruginosa and $C$ albicans were also sensitized by the dye but showed a slight microbial reduction with $(\mathrm{P}+\mathrm{L}+30)$, as did $S$ aureus $(P>.05)$; $E$ coli presented an initial score of 3 and achieved a bacterial reduction to score 2 with $(P+L+30)(P=.039)$.

Conclusions. Photodynamic therapy was effective in reducing $E$ coli counts on biofilms formed on acrylic resin specimens. The inhibition of microorganism growth tended to be directly proportional to the amount of energy provided by the light-emitting diode. (J Prosthet Dent 2014;112:632-637)

\section{CLINICAL IMPLICATIONS}

Photodynamic therapy promises to be an effective method for sterilizing acrylic resin. Future developments should allow clinicians to use this technique to sterilize removable prostheses and surgical guides quickly, with no damage to the acrylic resin.

Presented at 90th General Session \& Exhibition of the International Association for Dental Research, Iguaçu Falls, Brazil, June 2012.

\footnotetext{
${ }^{a}$ Adjunct Professor, Department of Restorative Dentistry.

${ }^{b}$ Private practice, Fortaleza, Brazil.

${ }^{\mathrm{c}}$ Postgraduate student, Postgraduate Program in Dentistry.

${ }^{d}$ Graduate student, School of Pharmacy, Dentistry and Nursing.

${ }^{\mathrm{e}}$ Postgraduate student, Postgraduate Program in Dentistry.
} 
Photodynamic therapy (PDT), also called photodynamic inactivation or antimicrobial photodynamic chemotherapy, is a therapeutic modality that has shown promise in the inactivation of pathogenic microorganisms. ${ }^{1-5} \mathrm{Re}$ ports date back over 100 years on the photodynamic effects of chemical compounds against microorganisms, ${ }^{6}$ which were reduced by the popularization of sulfonamides and penicillin. This technique is also used in oncology to effectively treat cancerous lesions through the induction of irreversible damage to the neoplastic tissue cells. ${ }^{7-10}$ Given the difficulties posed by the emergence of antimicrobial resistance, researchers have been seeking alternative solutions for the treatment of oral infections. Some studies have demonstrated the potential of PDT in the inactivation of microorganisms, including some types of viruses, bacteria, and fungi. $5,11,12$

PDT is the association of a photosensitizing agent to a light source in order to cause microbial cell necrosis and death. The action takes place when the photosensitizing dye absorbs photons and passes electrons to an excited state. In the presence of a substrate such as oxygen, the photosensitizer transfers energy to the substrate in order to return to its natural state. Shortlived highly reactive molecules such as singlet oxygen are formed, which can cause serious damage to cellular components of microorganisms. ${ }^{6}$ Methylene blue in different concentrations and conjugated to a red light source such as a laser or light-emitting diode (LED) has shown antimicrobial efficacy. ${ }^{13-16}$

Because of the mechanism of PDT, it is unlikely that an organism develops resistance to this type of therapy. ${ }^{6,17}$ Other advantages may also be observed with the use of photodynamic inactivation, including the selectivity of the photosensitizer, focalization of light on the region of interest only, possibility of repeating the therapy without cumulative toxic effects, noninvasiveness, and low risk. ${ }^{3}$ PDT has been used effectively in dentistry in the areas of cariology, periodontology, endodontics, and oral pathology. ${ }^{16,18-26}$

In prosthodontic treatment, a reduction in the number of microorganisms would improve the control of cross-infection between the dental office and dental laboratory. Strict asepsis is needed for immediate dentures and the surgical guides used in implant dentistry. Removable dental prostheses and surgical guides are fabricated from acrylic resin, which can be sterilized by ethylene oxide gas, gamma rays, immersion in a $2 \%$ glutaraldehyde solution for 10 hours, or microwave irradiation. Ethylene oxide gas and gamma rays are used in hospitals and have a high cost. The main disadvantage of $2 \%$ glutaraldehyde is the long immersion time required. Although promising, microwave irradiation has not been shown to provide $100 \%$ microbial elimination and may adversely affect the dimensional stability and hardness of the resin. ${ }^{27-29}$ The use of different concentrations of sodium hypochlorite and $70 \%$ ethanol have been reported for disinfection of acrylic resins. ${ }^{30-32}$ The immersion of acrylic resin in sodium hypochlorite for 10 minutes increased the surface roughness and decreased flexural strength, favoring the adhesion of microorganisms on the denture surface. Immersion in $70 \%$ ethanol for 15 minutes caused qualitative changes in the acrylic resin surface, as observed by scanning electron microscope. ${ }^{33}$

The search for a simple alternative method of disinfection or sterilization of acrylic resin devices is of interest to clinical dentistry because of problems of cross-infection between the laboratory and dental office and the use of nonsterile immediate dentures and surgical guides. ${ }^{31}$ In addition, a wide range of potentially pathogenic microorganisms has been found in previously worn dentures. ${ }^{34}$ PDT has proved to be an efficient, low-cost option to solve these problems. ${ }^{5,6,24}$ This in vitro study aimed to evaluate the antimicrobial efficacy of PDT against 5 different groups of microorganisms (Streptococcus mutans, Staphylococcus aureus, Escherichia coli, Pseudomonas aeruginosa, and Candida albicans) inoculated onto acrylic resin specimens to simulate the contaminated prosthetic parts of acrylic resin devices used in prosthodontics and implantology. The null hypothesis was that methylene blue at $0.05 \%$ would not be effective as a photosensitizing agent associated with a LED of red wavelength $(630 \mathrm{~nm})$ at 10 and $30 \mathrm{~J} / \mathrm{cm}^{2}$.

\section{MATERIAL AND METHODS}

A power analysis was performed with software (BioEstat 5.3; Mamirauá Institute) to determine sample size. Data were obtained from a pilot study, including the difference between the means of the $\mathrm{P}-\mathrm{L}-$ and $\mathrm{P}+\mathrm{L}+$ groups $(=1.2)$, error standard deviation $(=0.12)$, and number of treatments $(=7)(\alpha=.05)$. This test stated that 4 specimens per group were sufficient for a $90 \%$ probability of the statistical analysis to reject the null hypothesis $\left(\mathrm{H}_{0}\right)$ when the $\mathrm{H}_{0}$ was actually false (power of the test $=.90$ ). Therefore, 5 specimens per group $(n=5)$ were used.

A representative heat-polymerized acrylic resin (Lucitone 550; Dentsply Ind Com Ltd) which is used for the fabrication of complete dentures, partial removable dentures, and surgical guides for implants was selected for this study. Acrylic resin formers $(15 \mathrm{~mm} \times 15 \mathrm{~mm} \times$ $4 \mathrm{~mm}$ ), were embedded in metal flasks (Jon \#6; Jon) with Type III dental stone (Herodent; Vigodent S/A Ind Com).

After the formers had been removed, the acrylic resin was mixed (21 g powder, $10 \mathrm{~mL}$ liquid), placed in the mold in the plastic phase, and polymerized according to the manufacturer's instructions (immersion in water at $73^{\circ} \mathrm{C}$ for 90 minutes and at $100^{\circ} \mathrm{C}$ for 30 minutes). After bench cooling and deflasking, the test specimens were immersed in distilled water at $50^{\circ} \mathrm{C}$ for 24 hours to eliminate residual monomer. The surfaces of each specimen were finished with 150-, 220-, 400-, 600-, 1200-, and 2000-grit abrasive paper (Norton Indústria Brasileira) and polished with wet rag wheels (Invicta), felt cones, and canvas polishing disks with pumice slurry followed 
by calcium carbonate. The polished specimens were randomly distributed by drawing lots into groups $(n=5)$, sealed in surgical-grade paper envelopes (Veda Max; Zermatt Ind Com Ltda), and sterilized with ethylene oxide gas (White Martins) in sterilizer equipment (UN.SUPR; Sercon).

Methylene blue (Vetec Fine Chemicals Ltd) at a concentration of $0.05 \%$ was selected as the photosensitizer. The light source was a red LED of $630 \mathrm{~nm}$ and output power of $150 \mathrm{~mW}$ (MMOptics Ltda), with variable energy intensities of $10 \mathrm{~J} / \mathrm{cm}^{2}$ and $30 \mathrm{~J} / \mathrm{cm}^{2}$. The blue photosensitizer was coupled with the red LED because of the compatibility of the wavelength of this light source with the absorption band of the dye.

The microorganisms tested were Streptococcus mutans, provenance American Type Culture Collection (ATCC) 25175, and Staphylococcus aureus ATCC 25923, both with the morphotintorial characteristics of gram-positive cocci; Escherichia coli ATCC 11205 and Pseudomonas aeruginosa ATCC 10145, both with the morphotintorial characteristics of gram-negative cocci; and Candida albicans ATCC 001, yeast. These microorganisms underwent processes of activation, resuspension, and readout in a spectrophotometer (Ultrospec 1100 pro; Amersham Biosciences) in order to obtain a culture medium broth (brainheart infusion broth; Acumedia) with a microbial inoculum of $1 \%$ at $0.5 \mathrm{McF}$ arland scale, corresponding to $10^{6}$ colonyforming units $(\mathrm{CFU}) / \mathrm{mL}^{5,11,12,35}$ The absorbances used were 0.08 , at a wavelength of $590 \mathrm{~nm}$ for Streptococcus mutans, between 0.08 and 0.10 at a wavelength of $652 \mathrm{~nm}$ for Staphylococcus aureus, 1.43 at a wavelength of $600 \mathrm{~nm}$ for Escherichia coli, 0.64 at a wavelength of $600 \mathrm{~nm}$ for Pseudomonas aeruginosa, and 0.28 at a wavelength of $530 \mathrm{~nm}$ for Candida albicans. Specimen contamination consisted of their immersion in $15 \mathrm{~mL}$ of contaminated culture medium broth in individual falcon-type tubes. After this, the tubes containing the immersed test specimens were incubated at $37^{\circ} \mathrm{C}$ for 48 hours.
For each microorganism, the specimens were distributed into the following groups: P-L-, which were inoculated but not stained and not irradiated; $\mathrm{P}+\mathrm{L}-$, which were inoculated and stained but not irradiated; P-L+ 10 , which were inoculated, not stained, but irradiated by the light source at $10 \mathrm{~J} / \mathrm{cm}^{2} ; \mathrm{P}-\mathrm{L}+30$, which were inoculated, not stained, but irradiated by the light source at $30 \mathrm{~J} / \mathrm{cm}^{2} ; \mathrm{P}+\mathrm{L}+10$, which were inoculated, stained, and irradiated at $10 \mathrm{~J} / \mathrm{cm}^{2} ; \mathrm{P}+\mathrm{L}+30$, which were inoculated, stained, and irradiated at $30 \mathrm{~J} / \mathrm{cm}^{2}$; and GS (gold standard), which were sterilized in ethylene oxide gas. The P-L- group was the negative control to test the effectiveness of the contamination of the specimens, whereas the GS was the positive control and verified the effectiveness of previous sterilization with ethylene oxide gas. Each contaminated specimen was stained on all its surfaces with the $0.05 \%$ methylene blue. They were then irradiated with the red LED for the time necessary to achieve the levels of energy $10 \mathrm{~J} / \mathrm{cm}^{2}$ and $30 \mathrm{~J} / \mathrm{cm}^{2}$, according to the experimental design (Fig. 1).

After the treatments, each specimen was placed in contact with the culture medium agar (brain-heart infusion broth and Sabouraud dextrose; Acumedia) in separate petri plates $(20 \times$ $100 \mathrm{~mm}$ ). After 10 minutes, the specimens were discarded, and the plates were incubated at $37^{\circ} \mathrm{C}$ for 48 hours. Five petri plates per group were used. After the incubation period, the CFU were counted and the data were expressed according to the following scores: 1 , corresponding to $0 \mathrm{CFU} ; 2$, corresponding to 1 to $10 \mathrm{CFU}$; 3 , corresponding to 11 to $100 \mathrm{CFU}$; and 4, corresponding to 101 to $1000 \mathrm{CFU}$. The scores for each group were statistically analyzed by the Friedman and Dunn multiple comparison tests $(\alpha=.05)$.

\section{RESULTS}

The negative control of the $S$ mutans group of specimens (P-L-) was scored between 3 and 4 ; when treated only

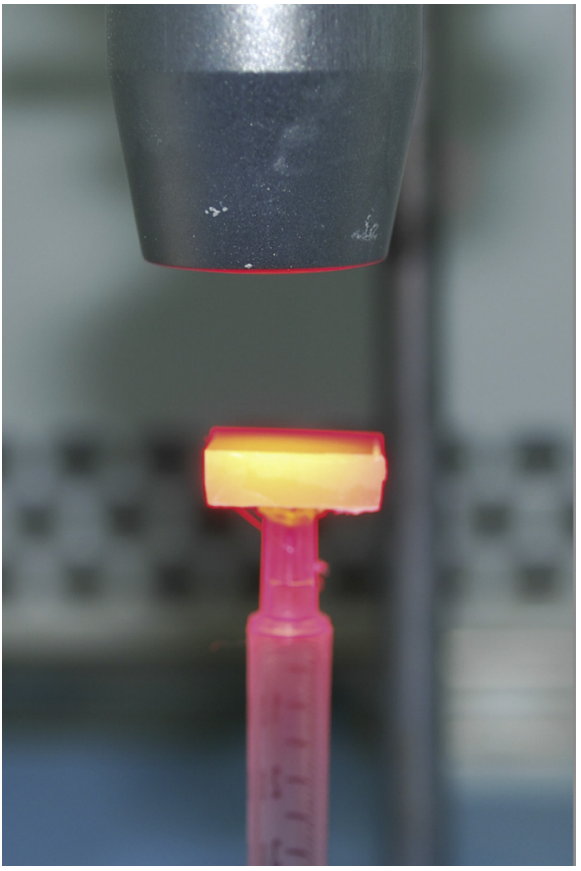

Application of PDT on acrylic resin specimen.

with the light (P-L+), no effect was observed. The use of methylene blue alone $(\mathrm{P}+\mathrm{L}-)$ decreased the scores to a range of 3 to 2 , and adding irradiation $(\mathrm{P}+\mathrm{L}+)$ did not result in an additional effect $(P=.37)$ (Fig. 2).

The negative control of the $S$ aureus group of specimens (P-L-) was scored 3 ; when treated only with light $(\mathrm{P}-\mathrm{L}+$ ) or photosensitizer ( $\mathrm{P}+\mathrm{L}-)$, no effect was observed; the PDT with irradiation at $10 \mathrm{~J} / \mathrm{cm}^{2}(\mathrm{P}+\mathrm{L}+10)$ had no effect either, whereas the PDT with irradiation at $30 \mathrm{~J} / \mathrm{cm}^{2} \quad(\mathrm{P}+\mathrm{L}+30)$ slightly decreased the CFU count to a score range of 3 to 2 , which was not statistically significant $(P=.12)$ (Fig. 3).

The negative control of the $E$ coli group of specimens was scored 3 ; when treated only with light $(\mathrm{P}-\mathrm{L}+)$ or photosensitizer ( $\mathrm{P}+\mathrm{L}-)$, no effect was observed; the PDT with irradiation at $10 \mathrm{~J} / \mathrm{cm}^{2}(\mathrm{P}+\mathrm{L}+10)$ had no effect either, whereas the PDT with irradiation at $30 \mathrm{~J} / \mathrm{cm}^{2}(\mathrm{P}+\mathrm{L}+30)$ significantly decreased the CFU count to score 2 ( $P=.04)$ (Fig. 4).

The negative control of the $P$ aeruginosa group of specimens was scored 3; when treated only with light $(\mathrm{P}-\mathrm{L}+)$, a slight decrease of CFU count was 


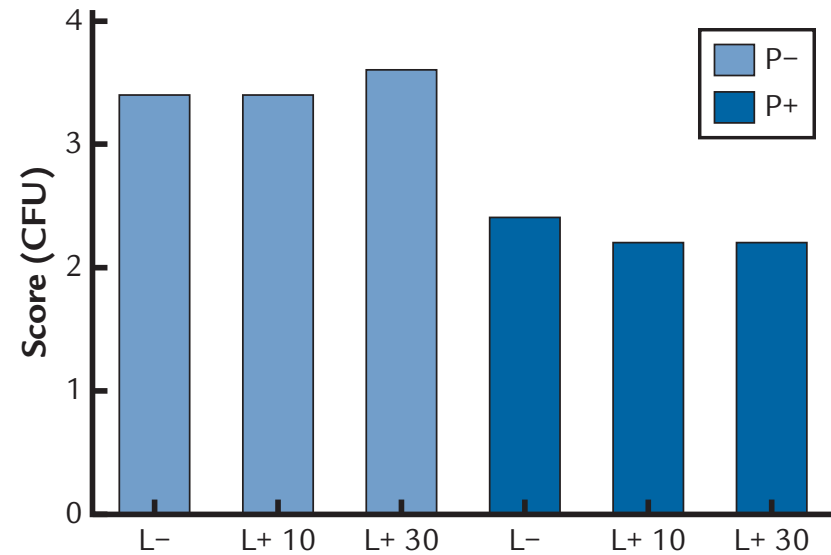

2 CFU count of $S$ mutans after treatments. P-, unstained groups; P+ stained groups; L-, unirradiated groups; $\mathrm{L}+$, irradiated groups $\left(\mathrm{J} / \mathrm{cm}^{2}\right)$.

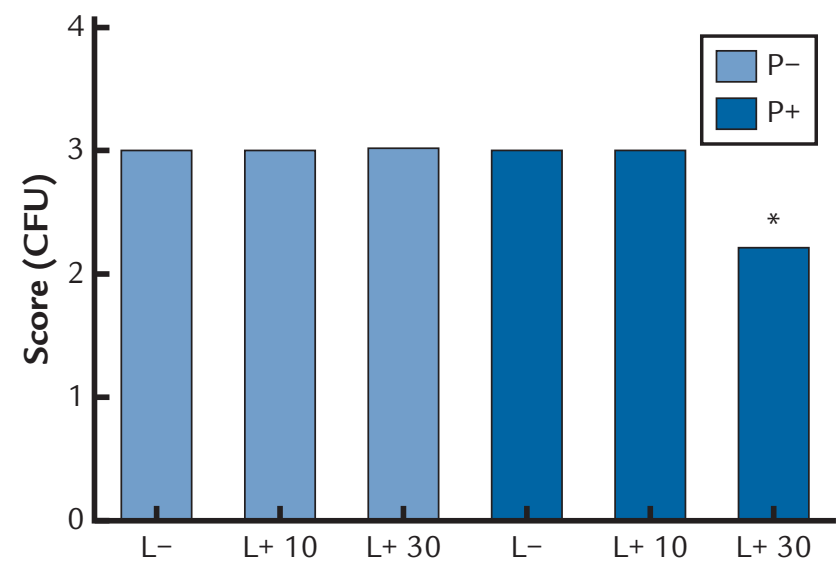

4 CFU count of $E$ coli after treatments. P-, unstained groups; $\mathrm{P}+$ stained groups; $\mathrm{L}-$, unirradiated groups; $\mathrm{L}+$, irradiated groups $\left(\mathrm{J} / \mathrm{cm}^{2}\right) ;{ }^{*} P=.0394$.

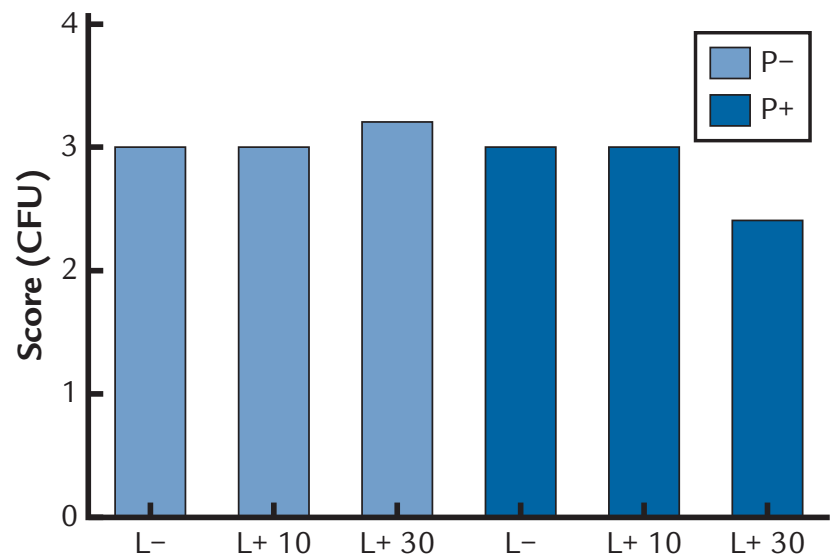

3 CFU count of $S$ aureus after treatments. $\mathrm{P}-$, unstained groups; $\mathrm{P}+$ stained groups; $\mathrm{L}-$, unirradiated groups; $\mathrm{L}+$, irradiated groups $\left(\mathrm{J} / \mathrm{cm}^{2}\right)$.

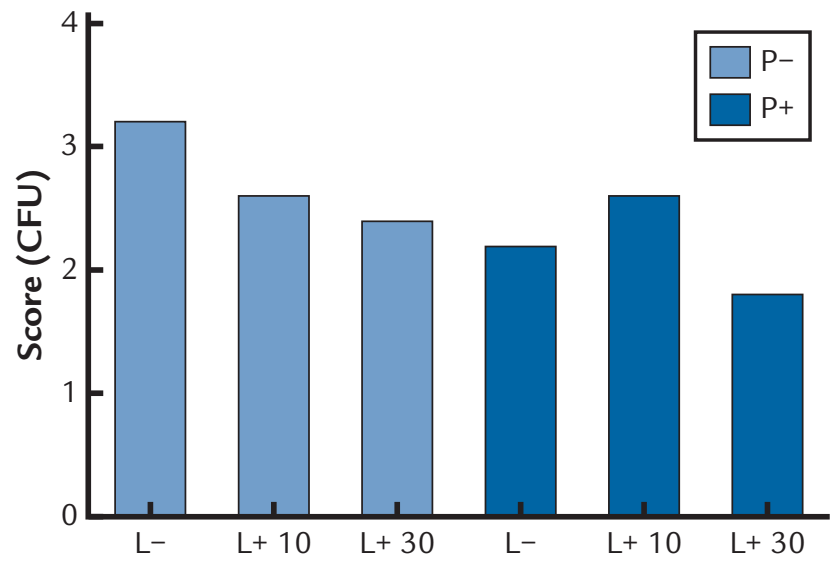

5 CFU count of $P$ aeruginosa after treatments. P-, unstained groups; $\mathrm{P}+$ stained groups; $\mathrm{L}-$, unirradiated groups; L+, irradiated groups $\left(\mathrm{J} / \mathrm{cm}^{2}\right)$. observed ( $P=.18)$. The use of methylene blue alone $(\mathrm{P}+\mathrm{L}-)$ decreased the scores to a range of 3 to 2 , and adding irradiation $(\mathrm{P}+\mathrm{L}+)$ did not result in an additional effect ( $P=.37)$ (Fig. 5).

The negative control of the $C$ albicans group of specimens was scored 4 ; when treated only with light ( $\mathrm{P}-\mathrm{L}+$ ), no effect was observed $(P=.69)$. The use of photosensitizer alone $(\mathrm{P}+\mathrm{L}-)$ decreased the CFU count to score 3 , and adding irradiation at $30 \mathrm{~J} / \mathrm{cm}^{2}(\mathrm{P}+\mathrm{L}+30)$ resulted in a slight additional effect $(P=.09)$ (Fig. 6).

The GS groups, whose specimens were sterilized in ethylene oxide gas, showed no microbial growth. For this reason, this group was not used for statistical comparisons.

\section{DISCUSSION}

Data from this study led to partial rejection of the null hypothesis. Differences were observed among the microorganisms tested because the PDT presented different results for each microorganism.

Streptococcus mutans was sensitive to $0.05 \%$ methylene blue dye alone, showing a reduction in counts when only stained, but not associated with light. Rolim et $\mathrm{al}^{26}$ reported that 327 $\mu \mathrm{M}$ methylene blue associated with a red LED at $24 \mathrm{~J} / \mathrm{cm}^{2}$ was not effective against $S$ mutans, although Pereira et $\mathrm{al}^{5}$ had presented efficacy with 0.01 $\mathrm{mg} / \mathrm{mL}$ methylene blue and InGaAlP red laser at $350 \mathrm{~J} / \mathrm{cm}^{2}$ against this microorganism. For specimens inoculated with $\mathrm{S}$ aureus, group $\mathrm{P}+\mathrm{L}+30$ showed a reduction in rates of bacterial growth, but this was not statistically significant. These bacteria were not sensitive to methylene blue alone. The group $\mathrm{P}+\mathrm{L}+30$ for $E$ coli showed a significant reduction in the number of CFU. The specimens inoculated with $P$ aeruginosa also showed a sensitivity of this microorganism to the methylene blue dye, reducing the CFU count by a score of 1 . In addition, they presented a slight sensitivity to the light alone. $C$ albicans did not present any sensitivity to the red LED but presented a sensitivity to methylene blue alone and conjugated with the red light at 10 and $30 \mathrm{~J} / \mathrm{cm}^{2}$, showing a progressive but 


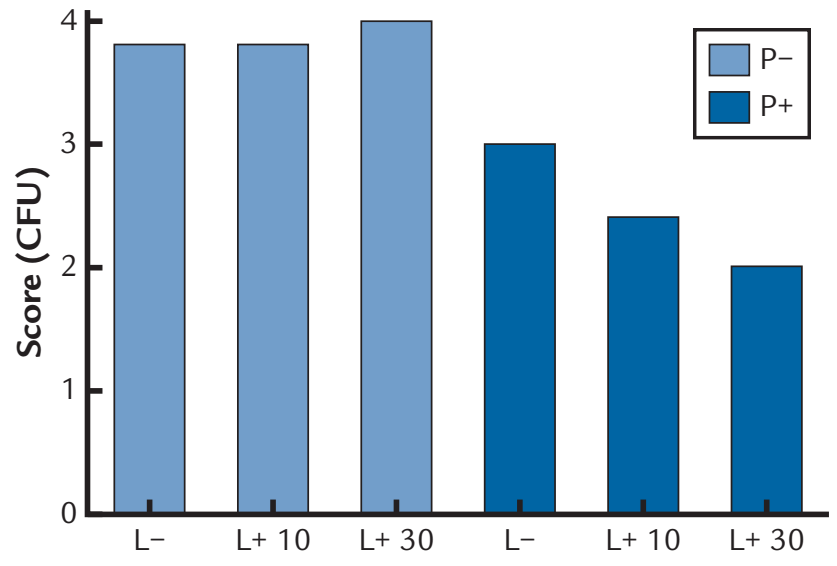

6 CFU count of $C$ albicans after treatments. $P-$, unstained groups; $\mathrm{P}+$ stained groups; $\mathrm{L}-$, unirradiated groups; $\mathrm{L}+$, irradiated groups $\left(\mathrm{J} / \mathrm{cm}^{2}\right)$.

statistically insignificant reduction in the CFU count. Pereira et $\mathrm{al}^{5}$ reported the efficacy of PDT against $S$ aureus and $C$ albicans biofilms by using higher concentration of dye and higher levels of light energy. This study sought to use a low dye concentration in order to avoid discoloration of the acrylic resin and a low-energy dose of LED to decrease the irradiation time required. However, these parameters were only significantly effective for $E$ coli biofilm.

Among the controls for almost all microorganisms, groups P-L- and P-L+ showed a large number of CFU, whereas the GS did not show any microbial growth. This determined that there was a real single species biofilm formation in inoculated specimens, in accordance with other studies, 5,12,35 and that the ethylene oxide gas sterilization was also effective. The isolated action of light source had almost no effect on the microorganisms, whereas the photosensitizer reduced the count of some microorganisms in the $\mathrm{P}+\mathrm{L}$ - groups.

Wood et $\mathrm{al}^{17}$ reported that the action of erythrosine at a concentration of $22 \mu \mathrm{M}$, without irradiation, had a negligible effect on $S$ mutans compared to the control group, which was not stained and not irradiated. Mima et $\mathrm{al}^{23}$ observed that Photogem $50 \mathrm{mg} / \mathrm{L}$ and a blue LED, when not associated, also produced a negligible antimicrobial effect. Miyabe et $\mathrm{al}^{11}$ reported that only laser irradiation or a $3 \mathrm{mM}$ concentration of methylene blue alone failed to reduce the count of Staphylococcus spp significantly. Costa et $\mathrm{al}^{12}$ found the same results by using erythrosine 0.39 to $200 \mu \mathrm{M}$ and laser $532 \mathrm{~nm}$. The concentration of the photosensitizer, the light source, and the species of microorganisms may promote variation in results. A tendency was also observed toward a reduction in the microorganism count with an increase in the energy applied by the light source. This finding was in agreement with that of Queiroga et al, ${ }^{15}$ who reported a decrease in the $C$ albicans count by raising the amount of energy provided by the red laser to $180 \mathrm{~J} / \mathrm{cm}^{2}$.

Some specimen groups presented intense microbial growth that resulted in colony aggregation, which made an exact count impossible. Therefore, because data do not allow a parametric description, an ordinal scale was used. This solution was taken, with some changes, from a study with a similar methodology performed by Paranhos et al. ${ }^{35}$

The following limitations of the study are noted. Only the surface of the specimen that came into contact with the culture medium agar in the petri plates was light irradiated. The treatment of the whole specimen could have avoided possible contamination from other areas that had not been fully irradiated and may have provided more effective values of microbial death. Irradiation with the red LED of $150 \mathrm{~mW}$, at energy intensity higher than $30 \mathrm{~J} / \mathrm{cm}^{2}$, would demand a long exposure time, which is not desirable. A more powerful machine in the same wavelength might have produced more effective results because energy is power multiplied by irradiation time. The inoculation in this study, although similar to other studies, ${ }^{5,11,12,35}$ was of great magnitude $\left(10^{6} \mathrm{CFU} / \mathrm{mL}\right)$. A lower microbial load might have produced improved results.

Additional studies are necessary to establish a protocol for sterilizing acrylic resin specimens with PDT by evaluating higher amounts of energy in light sources of different wavelengths and lower concentrations of various photosensitizers. Clinical trials are also necessary. This study represents a starting point for a promising line of research.

\section{CONCLUSIONS}

On the basis of the results and within the limitations of this study, it can be concluded that PDT with $0.05 \%$ methylene blue as photosensitizer and a $630 \mathrm{~nm}$ LED significantly reduced the microbial count in the $E$ coli biofilms formed on acrylic resin specimens. For $S$ mutans, $S$ aureus, $P$ aeruginosa, and $C$ albicans biofilms, an adjustment of protocol parameters is needed. Furthermore, the inhibition of microorganism growth tended to be directly proportional to the amount of energy provided by the light source: although $10 \mathrm{~J} / \mathrm{cm}^{2}$ was not effective, irradiation with $30 \mathrm{~J} / \mathrm{cm}^{2}$ showed more promising results.

\section{REFERENCES}

1. Wilson M, Dobson J. Lethal photosensitization of oral anaerobic bacteria. Clin Infect Dis 1993;16:414-5.

2. Wainwright M. Photodynamic antimicrobial chemotherapy. J Antimicrobial Chemother 1998;42:13-28.

3. Teichert MC, Jones JW, Usacheva MN, Biel MA. Treatment of oral candidiasis with methylene blue-mediated photodynamic therapy in an immunodeficient murine model. Oral Surg Oral Med Oral Pathol Oral Radiol Endod 2002;93:155-60. 
4. Donnelly RF, Mccarron PA, Tunney MM, David Woolfson A. Potential of photodynamic therapy in treatment of fungal infections of the mouth. Design and characterisation of a mucoadhesive patch containing toluidine blue $\mathrm{O}$. J Photochem Photobiol B 2007; 86:59-69.

5. Pereira CA, Romeiro RL, Costa AC, Machado AK, Junqueira JC, Jorge AO. Susceptibility of Candida albicans, Staphylococcus aureus, and Streptococcus mutans biofilms to photodynamic inactivation: an in vitro study. Lasers Med Sci 2011;26:341-8.

6. Konopka K, Goslinski T. Photodynamic therapy in dentistry. J Dent Res 2007;86: 694-707.

7. Dougherty TJ, Grindey GB, Fiel R, Weishaupt KR, Boyle DG. Photo radiation therapy II. Cure of animal tumors with hematoporphyrin and light. J Natl Cancer Inst 1975;55:115-9.

8. Woodburn KW, Fan Q, Kessel D, Wright M, Mody TD, Hemmi G, et al. Phototherapy of cancer and atheromatous plaque with texaphyrins. J Clin Laser Med Surg 1996;14: 343-8.

9. Sibata H, Colussi VC, Oleinick NL, Kinsella TJ. Photodynamic therapy: a new concept in medical treatment. Braz J Med Biol Res 2000;33:869-80.

10. Tardivo JP, Del Giglio A, Paschoal LH, Baptista MS. New photodynamic therapy protocol to treat AIDS-related Kaposi's sarcoma. Photomed Laser Surg 2006;24: 528-31.

11. Miyabe M, Junqueira JC, Costa ACBP, Jorge AOC, Ribeiro MS, Feist IS. Effect of photodynamic therapy on clinical isolates of Staphylococcus spp. Braz Oral Res 2011;25: 230-4.

12. Costa ACBP, Rasteiro VMC, Pereira CA, Hashimoto ESHS, Beltrame M Jr, Junqueira JC, et al. Susceptibility of Candida albicans and Candida dubliniensis to erythrosine and LED mediated photodynamic therapy. Arch Oral Biol 2011;56:1299-305.

13. Klepac CV, Patel N, Song X, Holewa C, Patel C, Kent R, et al. Photodynamic effects of methylene-blue loaded polymeric nanoparticles on dental plaque bacteria. Lasers Surg Med 2011;43:600-6.

14. Pupo YM, Gomes GM, Santos EB, Chaves L, Michel MD, Kozlowski VA Jr, et al. Susceptibility of $C$. albicans to PDT using methylene blue and toluidine blue as photosensitizing dyes. Acta Odontol Latinoam 2011;24: 188-92.

15. Queiroga AS, Trajano VN, Lima EO, Ferreira AF, Limeira FA. In vitro photodynamic inactivation of Candida spp by different doses of low power laser light. Phodiagnosis Photodyn Ther 2011; 8:332-6.
16. Noro Filho GA, Casarin RC, Casati MZ, Giovani EM. Photodynamic therapy in non-surgical treatment of periodontitis in HIV patients: a split-mouth, randomized clinical trial. Lasers Surg Med 2012;44: 296-302.

17. Wood S, Metcalf D, Devine D, Robinson C. Erythrosine is a potential photosensitizer for the photodynamic therapy of oral plaque biofilms. J Antimicrob Chemother 2006;57: 680-4.

18. Aghahosseini F, Arbabi-Kalati F, Fashtami LA, Fateh M, Djavid GE. Treatment of oral lichen planus with photodynamic therapy mediated methylene blue: a case report. Med Oral Patol Oral Cir Bucal 2006;11:126-9.

19. Foschi F, Fontana CR, Ruggiero K, Riahi R, Vera A, Doukas AG, et al. Photodynamic inactivation of Enterococcus faecalis in dental root canals in vitro. Lasers Surg Med 2007;39:782-7.

20. Oliveira RR, Schwartz-Filho HO, Novaes AB Jr, Taba M Jr. Antimicrobial photodynamic therapy in the non-surgical treatment of aggressive periodontitis: a preliminary randomized controlled clinical study. J Periodontol 2007;78:965-73.

21. Garcez AS, Nuñez SC, Hamblin MR, Ribeiro MS. Antimicrobial effects of photodynamic therapy on patients with necrotic pulps and periapical lesion. J Endod 2008;34:138-42.

22. Qin $Y L$, Luan $X L$, Bi LJ, Sheng $Y Q$, Zhou $C N$, Zhang ZG. Comparison of toluidine blue-mediated photodynamic therapy and conventional scaling treatment for periodontitis in rats. J Periodontal Res 2008;43:162-7.

23. Mima EG, Pavarina AC, Ribeiro DG, Dovigo LN, Vergani CE, Bagnato VS. Effectiveness of photodynamic therapy for the inactivation of Candida spp on dentures: in vitro study. Photomed Laser Surg 2011;29: 827-33.

24. Parker S. Photodynamic antimicrobial chemotherapy in dental practice. Dent Nurs 2011;7:380-5.

25. Nagata JY, Hioka N, Kimura E, Batistela VR, Terada RS, Graciano AX, et al. Antibacterial photodynamic therapy for dental caries: evaluation of the photosensitizers used and light source properties. Photodiagnosis Photodyn Ther 2012;9:122-31.

26. Rolim JP, de-Melo MA, Guedes SF, Albuquerque-Filho FB, de Souza JR, Nogueira NA, et al. The antimicrobial activity of photodynamic therapy against Streptococcus mutans using different photosensitizers. J Photochem Photobiol B 2012; 106:40-6.

27. Dixon DL, Breeding LC, Faler TA. Microwave disinfection of denture base materials colonized with Candida albicans. J Prosthet Dent 1999;81:207-14.
28. Campanha N, Pavarina AC, Vergani C, Machado A. Effect of microwave sterilization and water storage on the Vickers hardness of acrylic resin denture teeth. J Prosthet Dent 2005;93:483-7.

29. Seo RS, Vergani CE, Pavarina AC, Compagnoni MA, Machado AL. Influence of microwave disinfection on the dimensional stability of intact and relined acrylic resin denture bases. J Prosthet Dent 2007;98: 216-23.

30. da Silva FC, Kimpara ET, Mancini MN, Balducci I, Jorge AO, Koga-Ito CY. Effectiveness of six different disinfectants on removing five microbial species and effects on the topographic characteristics of acrylic resin. J Prosthodont 2008;17:627-33.

31. Smith PN, Palenik CJ, Blanchard SB. Microbial contamination and the sterilization/ disinfection of surgical guides used in the placement of endosteal implants. Int J Oral Maxillofac Implants 2011;26:274-81.

32. Freitas Fernandes FS, Pereira-Cenci T, da Silva WJ, Ricomini Filho AP, Straioto FG, Del Bel Cury AA. Efficacy of denture cleansers on Candida spp biofilm formed on polyamide and polymethyl methacrylate resins. J Prosthet Dent 2011;105:51-8.

33. Odagiri K, Sawada T, Hori N, Seimiya K, Otsuji T, Hamada N, et al. Evaluation of denture base resin after disinfection method using reactive oxygen species (ROS). Dent Mater J 2012;31:443-8.

34. Glass RT, Conrad RS, Bullard JW, Goodson LB, Mehta N, Lech SJ, et al. Evaluation of microbial flora found in previously worn prostheses from the Northeast and Southwest regions of the United States. J Prosthet Dent 2010;103:384-9.

35. Paranhos HFO, Silva-Lovato CH, Souza RF, Cruz PC, Freitas-Pontes KM, Watanabe E, et al. Effect of three methods for cleaning dentures on biofilms formed in vitro on acrylic resin. J Prosthodont 2009;18:427-31.

Corresponding author:

Dr Karina Matthes de Freitas Pontes

Rua Monsenhor Furtado S/N, Rodolfo Teófilo

60430-350, Fortaleza, CE

BRAZIL

E-mail:kamatthes@yahoo.com.br

Acknowledgments

The authors thank Lidiany Karla de Azevedo Rodrigues, coordinator of Postgraduate Program in Dentistry, School of Pharmacy, Dentistry and Nursing, Federal University of Ceará, and Nadia Accioly Pinto Nogueira, professor of Postgraduate Program in Dentistry, School of Pharmacy, Dentistry and Nursing, Federal University of Ceará, for their collaboration in planning the microbiological experiments.

Copyright ( 2014 by the Editorial Council for The Journal of Prosthetic Dentistry. 